\title{
A Cross-linguistic Study of Person Agreement in Imposter Constructions
}

\author{
Kaori Furuya \\ University of North Texas/World Languages, Literatures, and Cultures, Texas, USA
}

\begin{abstract}
This paper provides an analysis of person agreement in the imposter phenomenon studied by Collins \& Postal (2012). In the constructions, full DPs are used to refer to speech-act participants like personal pronouns. Nonetheless, person agreement caused by imposters morphsyntactically varies in a subject-verb relation and subject-object relation cross-linguistically. Moreover, members of the classes of imposters are also not identical among languages. These patterns differ from those of personal pronouns. The paper argues that dual properties of the person feature (semantic and morphological) do not always coincide, leading to agreement alternations in PF. Furthermore, the D head does not always involve the person feature value, which induces dialectal and cross-linguistic variation. The analysis shows that regardless of the cross-linguistic variations, the syntactic operation for agreement is uniform in imposter constructions.
\end{abstract}

Index Terms - imposter, agreement, the person feature, DP, (under)specification

\section{INTRODUCTION}

Normally, full DPs such as this reporter are used to refer to a $3^{\text {rd }}$ party talked about that is not the speaker or the addressee. However, this is not always the case. Collins \& Postal (2012) report that these DPs can be used to denote the speakers, as shown in (1). ${ }^{1}$

(1) a. This reporter sent myself to cover Bill Clinton's lecture at the Pavilion...

(Collins \& Postal, 2012, p. 20)

b. This reporter sees himself as managing editor in the future.

c. These reporters respect ourselves/themselves.

(Collins \& Postal, 2012, p. 20)

(Collins \& Postal, 2012, p.54)

The subjects are used to refer to a speaker or a speaker's group. Interestingly, they select $1^{\text {st }}$ person reflexives in (1a, b) and $3^{\text {rd }}$ reflexives in $(1 b, c)$. Even when the subjects determine $3^{\text {rd }}$ person reflexives as in $(1 b, c)$, they can denote the speaker or the speaker's group. Importantly, Collins \& Postal (2012) explicitly state that "the agreement alternation is not accompanied by differences in truth conditions" (p. vii). This particular kind of a DP, which may exhibit distinct person agreement simultaneously, is what Collins \& Postal (2012) call imposter. ${ }^{2}$ Collins \& Postal $(2012$, p. 5) define an imposter in (2).

(2) An imposter is a notionally $n$ person DP which is grammatically $m$ person, $n \neq m$. (Collins \& Postal, 2012, p. 5)

According to Collins \& Postal, notional person is the semantic category associated with the discourse roles such as the speaker while grammatical person is a morphosyntactic property linked to notional person. For instance, the subject this reporter in (1) involves the reference to a speaker and morphologically shows $1^{\text {st }}$ person or $3^{\text {rd }}$ person agreement in binding. Collins \& Postal (2012) state "that there is not a strictly lawful connection such that a form whose notional person is $n$ inevitably has those morphosyntactic features associated in a particular language with $n$ person" (p.5). What is important here is that despite of the same reference, an imposter possibly shows distinct morphological properties (see also Corbett 2006). That suggests that semantic features and morphological features do not always coincide in agreement.

Since Collins \& Postal's (2012) observations of the agreement alternation caused by English imposters as in (1), a growing number of studies on agreement shown by imposters have recently reported morphosyntactic variation crosslinguistically (Wang, 2009; An et. al., 2016 for Chinese; Das, 2011 for Bengali; Soare, 2013 for French and Romanian; Dudley, 2014; Vazquez Rojas, 2014, for Spanish, Wood \& Sigurðsson, 2014 for Icelandic; Furuya, 2016 for Japanese; Akkuş, 2017 for Turkish, a. o.). Strikingly, the agreement alternation in (1) is not always observed among the attested languages. Questions arise. What types of person agreement displayed by imposters are cross-linguistically possible and what types are not? How is the co-existence of two sets of the person feature (i.e. semantic and grammatical person)

\footnotetext{
${ }^{1}$ Two remarks are listed here. First, Collins \& Postal (2012) report that many other such examples are found on the internet, although they accept only examples with $3^{\text {rd }}$ person reflexives when they are singular. However, they do accept $1^{\text {st }}$ person singular reflexives for the reference to the speaker in English, while they accept some long distance reflexive binding relations as in (i).

(i) (a) This reporter believes no one but himself/?myself capable of solving that problem. $\quad$ (Collins \& Postal, 2012, p. 22)

(b) Daddy doesn't consider Captain Marvel to be much different than himself/?myself. $\quad$ (Collins \& Postal, 2012, p. 22)

Secondly, Collins \& Postal (2012) observe that DPs can also be used to refer to an addressee or addressee's group. The present work concentrates exclusively on imposters that are used to refer to the speaker.

${ }^{2} \mathrm{An}$ imposter DP is different from an epithet in that the latter refers to the party talked about that is not the speaker or the addressee (Dubinsky \& Hamilton 1998; Collins \& Postal 2012, Chapter 11).
} 
correlated? To what extent could referential nominal expressions behave like personal pronouns cross-linguistically? This paper explores these questions.

This paper observes cross-linguistic variation of person agreement caused by imposters and that of their classes among the attested languages (Collins 2014). While showing that the variation for person agreement is possibly classified into a limited number of groups, the paper also exhibits language specific variations on the scopes of imposters. It argues that the variations are attributed to the lexicon and PF while the syntactic operation for agreement is uniform. The paper will not be concerned with an analysis of the gender and number feature although they are also assumed as elements of phi-features in syntax.

The structure of this paper is as follows. Section II provides two properties of imposters with Wechsler \& Zlatićs (2003) dual model of CONCORD-INDEX agreement: (i) morphosyntactic variation in person agreement in imposter constructions and (ii) the classes of imposters cross-linguistically. Section III offers an analysis of imposters and argues that the variation is attributed to the lexicon and PF. It also compares the proposed analysis with three extant analyses of person agreement. Section IV concludes the paper.

\section{CROSS-LINGUISTIC VARIATIONS OF IMPOSTERS}

The main goal of this paper is to provide an analysis of cross-linguistic variation in person agreement shown by DPs in imposter use. Before partaking this task, in this section I show two properties of imposters: (i) the morphosyntactic variation in light of person agreement with Wechsler \& Zlatić's (2003) CONCORD-INDEX model and (ii) the variation in the scope of imposter members.

\section{A. Cross-linguistic Variation in Light of Person Agreement Caused by Imposters}

In this subsection I examine cross-linguistic variation in person agreement caused by imposters. In generative grammar, phi-features are taken as formal and carry two sets of features: morphological and semantic. The person feature is no exception. In Chomsky's (1995) minimalist program, the person feature is a morphosyntactic feature. In HPSG, Wechsler \& Zlatic (2003) and Wechsler (2011) adopt the perspective that the person feature exists only as features of referential indices (INDEX feature) and never as morphological features (CONCODE feature). Both perspectives on the person feature is identical to each other when it is concerned about person agreement displayed by personal pronouns since semantic features and morphological features coincide.

In this paper I conventionally employ $\left[1^{\text {st }}\right]$ that represents the morphological property and [Speaker] that is associated with the semantic category (e.g. Harley \& Ritter, 2002) with Wechsler \& Zlatić's (2003) CONCORD-INDEX model and I assume both features as grammatical. Let us look at the person feature values of the English $1^{\text {st }}$ person pronoun $I$ in (3), as shown in (4).

(3) I look at myself / *himself in the mirror.

(4) The person feature of the $1^{\text {st }}$ person pronoun $I$

$\left[\begin{array}{lc}\text { INDEX | PERSON } & \text { Speaker } \\ \text { CONCORD | PERSON } & 1^{\text {st }}\end{array}\right]$

In (4), the value of the INDEX feature for person is [Speaker] and that of the CONCORD feature is [ ${ }^{\text {st }}$. In this case, both values uniquely encode into the personal pronoun $I$ and the two sets of the person feature coincide. Thus, the subject with these values for person determines a $1^{\text {st }}$ person reflexive; the selection of a $3^{\text {rd }}$ person reflexive is ungrammatical.

With the two types of values for the person feature, I present cross-linguistic variation in person agreement caused by an imposter cross-linguistically (Collins, 2014) by distinguishing them into two groups: one group shows agreement alternations, and the other does not exhibit alternations. The first group of languages displays $1^{\text {st }}$ and $3^{\text {rd }}$ person agreement alternations as in English. The languages in this group include Albanian (Kallulli, 2014), Brazilian Portuguese (Taylor, 2009), French (Soare, 2013), Icelandic (Wood \& Sigurðsson, 2014), Romanian (Soare, 2013), Spanish (Dudley, 2014, Vazquez Rojas, 2014), and Turkish (Akkuş, 2017). Importantly, while not all languages explicitly display the harmony between verbal agreement and pronominal agreement, Spanish shows that the harmony must hold in light of person in (5); otherwise the sentences are ungrammatical in (6).
a. Unos servidores some servants quedamos en decided.1P on

encontrar-nos

a las siete.

Spanish

'These guys (=speakers) decided to meet each other at seven.'

$\begin{array}{lllll}\text { b. Unos servidores } & \text { quedaron } & \text { en encontrar-se } & \text { a las siete. } \\ \text { some servants } & \text { decided.3PL } & \text { on to.meet-themselves } & \text { at the.PL seven }\end{array}$ 'These guys (=speakers) decided to meet each other at seven.'

\section{(Adapted from Dudley, 2014, P. 50)}
a. *Estas periodistas
decidieron unir-nos
en promover esta causa. these reporters decided.3PL
b. *Unos servidores quedamos
en encontrar-se
a las
siete al
lado del
Spanish

014, p. 50)
Spanish 
some servants decided.1PL on to.meet-themselves at the.PL seven to.the side of.the theater

(Dudley 2014, p. 54)

The same subjects in $(5 \mathrm{a}, \mathrm{b})$ show $1^{\text {st }}$ and $3^{\text {rd }}$ person verbal agreement and yield a $1^{\text {st }}$ and $3^{\text {rd }}$ person reflexive respectively. By contrast, the subjects in $(6 \mathrm{a}, \mathrm{b})$ display mixed agreement. The verbal morphology in $(6 \mathrm{a})$ is $3^{\text {rd }}$ person but the reflexive is $1^{\text {st }}$ person. In (6b) the verb quedamos 'decide' exhibits $1^{\text {st }}$ person whereas the reflexive is $3^{\text {rd }}$ person. This mixed agreement is ungrammatical. This shows that subject-verb agreement and subject-object agreement should be compatible with each other in light of the person feature. What is also noteworthy is that the alternations are observed in both non-pro-drop languages (e.g. English) and pro-drop languages (e.g. Spanish).

A second language group gives rise to only one type of person agreement. Yet, the person agreement exhibited by this group of languages is not uniform. Wang (2009) reports that the Chinese imposter construction only displays $1^{\text {st }}$ person agreement in (7) (see also An et. al., 2016).

(7) A-Bian zhi hui tou gei $\{*$ ta-ziji / wo-ziji $\}$

A-Bian only will vote to he-self / I-self

'A-Bian (= I/speaker) will only vote for $\left\{{ }^{*}\right.$ himself / myself $\}$ '

Chinese

$(\mathrm{A}-\mathrm{Bian}=$ the nickname of a President $)$

Wang, 2009)

The imposter subject only binds the $1^{\text {st }}$ person reflexive wo-ziji 'myself', and the selection of the $3^{\text {rd }}$ person reflexive ta-ziji 'himself' is ungrammatical.

In contrast, Das (2011) and Servidio (2014) observe that Bengali and Italian only determine $3^{\text {rd }}$ person agreement in the imposter constructions in $(8 \mathrm{a}, \mathrm{b})$ respectively.
a. Baba rege ja-b-e / *ja-b-o. father angry go-FUT-3/go-FUT-1 'Daddy will get angry'

b. Gli autori cercheranno / *cercheremo the authors attempt.FUT.3PL attempt.FUT.1PL of 'The authors will try to defend themselves/*ourselves'
Bengali

(Das, 2011, p. 29)

difendere se stessi/*noi stessi. defend themselves/ ourselves

Italian

(Servidio, 2014, p. 125)

In (8a) the Bengali imposter only select $3^{\text {rd }}$ person verbal agreement. Similarly, in (8b) the Italian imposter also determines a $3^{\text {rd }}$ person reflexive besides the $3^{\text {rd }}$ person verbal morphology. In these cases, $1^{\text {st }}$ person agreement is not allowed.

Lastly, Furuya (2016) shows that a Japanese imposter selects the underspecified reflexive in (9).

(9) Sensei (= I)-wa kagami-de *watasizisin / *kanozyozisin / zibun-o mita. teacher-Top mirror-in myself herself self-Acc saw

Japanese

'Teacher (=I) saw *myself/*herself/self in the mirror.'

(Furuya, 2016, p. 1730)

The Japanese imposter can take the underspecified reflexive zibun 'self' (Kuno, 1973; Kuroda, 1973) and it cannot tolerate a $1^{\text {st }}$ person or $3^{\text {rd }}$ person reflexive.

To summarize, we observed the wider variety of morphosyntactic variation in light of person agreement in the attested languages than the English example shows in (1). While one group of languages shows $1^{\text {st }}$ and $3^{\text {rd }}$ person agreement alternations like English, the other group of languages only selects one type of agreement. Our observations of person agreement are summarized in (10).

(10) Person agreement by imposters

\begin{tabular}{|c|c|}
\hline Languages & Morphological realization via agreement \\
\hline $\begin{array}{c}\text { Albanian, English, French, Icelandic, Prorogue, } \\
\text { Romanian, Spanish, Turkish }\end{array}$ & $1^{\text {st }}$ or $3^{\text {rd }}$ \\
\hline Chinese & $1^{\text {st }}$ \\
\hline Bengali, Italian & $3^{\text {rd }}$ \\
\hline Japanese & underspecified \\
\hline
\end{tabular}

The chart elaborates on Collin and Postal's (2012) definition of imposters in (2) and shows that person agreement caused by imposters referring to the speaker or the speaker's group is not morphologically uniform cross-linguistically. A large number of cross-linguistic examples among the attested languages show $1^{\text {st }}$ and $3^{\text {rd }}$ person agreement alternations. Yet, some languages only show $1^{\text {st }}$ person, $3^{\text {rd }}$ person or underspecified for person. The chart can be reorganized in terms of the INDEX-CONCORD agreement in (11).

(11) Relation between INDEX and CONCORD features for imposters referring to speakers

\begin{tabular}{|c|c|}
\hline INDEX feature & CONCORD feature \\
\hline \multirow{2}{*}{ Speaker } & $1^{\text {st }}$ \\
\cline { 2 - 2 } & $3^{\text {rd }}$ \\
\cline { 2 - 2 } & underspecified \\
\hline
\end{tabular}


The value of the INDEX feature is [Speaker], whereas that of the CONCODE feature can be $1^{\text {st }}$ person, $3^{\text {rd }}$ person or underspecified. This indicates that the morphological realizations shown by an imposter with [Speaker] appear to be limited to three values of the person feature among the attested languages.

In the following subsection, I discuss cross-linguistic comparisons in light of members of the nominal classes used as imposters, and show similarities and differences cross-linguistically.

\section{B. The Classes of DPs as Imposters}

While overall imposter class is open, referential expressions that denote humans are possibly used as imposters. In this subsection, I closely look into the classes of imposters in English, Bengali, Chinese, Icelandic, and Spanish, and show that referential expressions can be used as imposters while there exist dialectal and cross-linguistic differences.

English Imposters

Collins \& Postal (2012) provide a fuller recognition of the scope of English imposters in (12) than previous studies of imposter usages (Stirling \& Huddlenston, 2002; Siewierska, 2004).

(12) English $1^{\text {st }}$ person imposters

a. Determiner/demonstrative/possessor (modifier) + nouns the (present) author(s): the court, the (present) writer(s), your faithful correspondent

b. Personal names: Jerome, Johns, Jerome (J.) Jones, the present Thomas Wilson Belmont

c. Members of the set of diminutive kinship terms: daddy, mommy, auntie, granny, gramps

d. Various nondiminutive kinship terms plus a personal name: Uncle + Name, Aunt + Name, Cousin + Name, Grampa + Name, Granma + Name

e. The + participles: the undersigned

(Adapted from Collins \& Postal 2012, pp. 7-8)

In (12a), the + (Modifier +) Common Noun and this/these + Common Noun can denote a speaker or a speaker's group when the common noun phrases bear titles or occupational roles. Moreover, proper names and kinship terms in $(12 \mathrm{~b}, \mathrm{c}, \mathrm{d})$ as well as the combination of the determiner the and participles (that denote human) in (12e) can also be used as imposters. Collins \& Postal note that number restriction exists in relation to person agreement alternations in some dialects of English including Collins \& Postal's dialect. In those dialects, there is a sharp difference in light of determining pronominal agreement between singular and plural imposters, as shown in (13).

(13) a. This reporter sees himself / *myself as managing editor in the future.

(Collins \& Postal 2012, p. 28)

b. This reporter and Jerome should disguise ourselves / themselves as ghosts.

(Collins \& Postal 2012, p. 172)

c. These reporters respect themselves/ourselves.

(Collins \& Postal 2012, p. 85)

The English singular imposter alone cannot antecede a non $-3^{\text {rd }}$ person reflexive in (13a) while no such restriction exists with the imposter conjunct and the plural counterpart in $(13 \mathrm{~b}, \mathrm{c})$. Thus, in some dialects number appears to be associated with the pronominal alternations in the English imposter construction, unlike in other dialects with no such number restriction.

Chinese Imposters

Wang's (2009) report on the scope of Chinese imposter DPs is similar to that of English in (12) (see also An et. al., 2016) and yet it appears to be simpler than (12), shown in (14).

(14) Chinese $1^{\text {st }}$ person imposters

a. Common nouns laoshi 'teacher', jizhe 'reporter', benren 'this person',

b. Personal names A-Bian 'Proper Name'

c. Kinship terms

The classes of nouns in $(14 \mathrm{a}, \mathrm{b})$ are exemplified in $(15 \mathrm{a}, \mathrm{b})$ respectively.

(Adapted from Wang, 2009)
(15) a. Laoshi zhende bu xihuan ma ren. teacher really Neg like scold person
'Teacher (= I) really doesn't like to scold anyone.'
b. Bizhe han tongshi qiwang *tamen-ziji/women-ziji keyi you xin faxian. author and colleague expect they-self we-self can have new finding 'The present author and colleague(s) expect *themselves / ourselves to have new findings.'

(Wang, 2009)

The common noun phrase laoshi 'teacher' and the proper noun bizhe 'author' in the subject positions are used to refer to the speaker. Chinese selects $1^{\text {st }}$ person agreement in the imposter constructions, and the selection of $3^{\text {rd }}$ person agreement is ungrammatical, as opposed to English, However, there are two minor differences between Chinese and English. According to Wang (2009) and An et. al. (2016), there is no singular and plural asymmetry in light of person agreement in the Chinese imposter construction. Moreover, the bare nouns appears to be used as imposters while they are definite expressions in (15). 
Bengali Imposters

Das (2011) observes the Bengali imposter construction and presents the scope of the class for Bengali imposters in (16).

(16) Bengali $1^{\text {st }}$ person imposters

a. Demonstrative + common nouns: ei sharma, ei mokkel 'this guy', ei sangbadik 'this reporter', ei chatro brinda 'this group of students'

b. Personal names: Archana Das 'Proper Name'

c. Kinship term: baba 'Daddy'

d. Determiner + adjective: nimna-sakkhorito 'the undersigned'

(Adapted from Das, 2011, p. 29)

This list for Bengali is similar to that of English and Chinese (with the exception of (16d) for Chinese). Yet, Bengali is different from these languages in that this language always determines $3^{\text {rd }}$ person agreement, as shown in (17).

$\begin{array}{cllllll}\text { (17) a. Ei sharma } & \text { shudhu tar } / * \text { amar } & \text { nijer } & \text { jonnoi } & \text { ranna kor-b-e } \\ \text { this guy } & \text { only } & \text { his my } & \text { self } & \text { for } & \text { cook } & \text { do-Fut-3 }\end{array}$

'This guy will only cook for himself'

b. Ei chatro-ra shudhu tader/*amader nijer jonnoi ranna kor-b-e

these student-Cla only their our self for cook do-Fut-3

'These students will only cook for themselves'

(Das, 2011, p. 30)

The singular and plural subject determine $3^{\text {rd }}$ person in person agreement with the verb and the reflexive. Selection of $1^{\text {st }}$ person agreement is ungrammatical. According to Das, this generalization holds for all kinds of imposters (singular, plural, coordinated) in Bengali.

Icelandic Imposters

Wood \& Sigurðsson (2014) offer the widest scope of imposters in Islandic among the five languages, as shown in (18)

(18) Icelandic $1^{\text {st }}$ person imposters

a. Demonstrative/determiner + noun: pessir fréttamenn 'these reporters'

b. Personal names: Jón 'John' or Jón fraendi 'Uncle John'

c. Kinship terms mamma 'Mommy', pabbi 'Daddy', 'Uncle John'

d. Adjectival participles undirritaður '(the) undersigned (sg)' and undirritaðir '(the) undersigned (pl)'

e. The demonstrative Sá 'the one'+ modifier: sá sem hér talar 'the one who is talking here'

f. Others: a noun with a definite suffix: karlinn 'the man / the old man', a 'weak' adjective gamli 'old'

(Adapted from Wood \& Sigurðsson, 2014, pp. 198-200)

(18a-d) appear to be identical to those of Bengali, Chinese and English. However, according to Wood \& Sigurðsson (2014), it seems that a micro-parametric variation exists in the scope of Icelandic imposters among speakers. In (18a), speakers seem to vary in whether they accept imposter uses of pessir fréttamenn 'these reporters'. Moreover, núverandi/viðstaddir höfundar 'the present authors' cannot be used as imposter in Icelandic, whereas höfundar pessarar greinar '(the) authors of this article' is possible. Three additional remarks is as follow. First, unlike English and Bengali, in (18d) Icelandic adjectival participles do not require a determiner to be used as imposters, as in (19).

(19) Undirritaður hefur / *hef ákveðið að hætta. undersigned.M.SG has.3SG $1 \mathrm{SG}$ decided to quit 'The undersigned (sg) has decided to quit.'

(Wood \& Sigurðsson, 2014, p. 207)

A second remark is regarding (18e). I assume that sá 'the one' requires a relative clause or some other kind of modifier to refer to a speaker. Lastly, according to Wood \& Sigurðsson, the use of imposters in (18f) has arisen recently among young speakers. These kinds of use are not observed in the other attested languages.

Spanish Imposters

Dudley's (2014) list of the scope of Spanish imposters in (20) is slightly different from the ones that are observed so far.

(20) Spanish $1^{\text {st }}$ person imposters

a. Determiner + plural NPs denoting human las mujeres 'the women'

b. Demonstrative + common noun: este estudiante 'this student'

c. Kinship terms tu hijo 'your son'

d. Determiner + 'undersigned' el firmante the undersigned'

e. Indefinite determiner + 'servant' un servidor 'a servant'

(Dudley, 2214, p. 43) 
Dudley reports that a Spanish imposter consisting of a determiner and common noun should be in plurality in (20a), while nominals with demonstratives do not appear to have such a restriction in (20b). The members in (20c, d) are listed in other languages, but Dudley states that proper names cannot be used as imposters in Spanish. Such a restriction does not seem be observed in the other languages observed so far. Moreover, unlike the other languages Spanish also allows the expression with an indefinite determiner un servidor 'a servant' to be used to refer to the speaker in (20e) (Vazquez Rojas, 2014). Dudley observes that the agreement pattern for un servidor 'a servant' selects only $3^{\text {rd }}$ person verbal agreement, whereas the plural imposter unos servidores 'some servants' optionally determines both $1^{\text {st }}$ and $3^{\text {rd }}$ person agreement. $^{3}$

These observations offer some rough indications of the scopes of the imposter classes in (21). For the imposter type represented by the definite article/demonstrative + noun such as the present reporter and these reporters, an infinite number of similar examples can be possibly found along with some variations in Icelandic (see 20e, f) in the attested examples except that Chinese, an article-less language, appears to allow bare common nouns to be used as imposters. Likewise, imposters based on proper names and kinship terms are also unlistable among languages in (21b). Moreover, participle forms often combined with the definite article can be used as imposters in English, Bengali, Icelandic and Spanish, along with some Icelandic adjective forms in (21c). What is noteworthy is that despite of having these similarities, Bengali only shows $3^{\text {rd }}$ person agreement and Chinese determines $1^{\text {st }}$ person agreement in imposter constructions, unlike English, Icelandic and Spanish, which allow $1^{\text {st }}$ and $3^{\text {rd }}$ person agreement. As for some number restriction, the singular-plural asymmetry in the agreement alternation exists in some dialects of English, Spanish, and Icelandic but not in other dialects of English besides Bengali, and Chinese in the attested examples in (21d). Yet, a singular imposter coordinated with another DP can show the agreement alternation cross-linguistically. What is also remarkable is that a Spanish DP with an indefinite article can be used as imposter in (21e).

(21) The scopes of imposter classes

\begin{tabular}{|c|c|c|c|c|c|}
\hline & English & Bengali & Chinese & Icelandic & Spanish \\
\hline a. (The definite article/demonstrative + ) noun & $\mathrm{o}$ & $\mathrm{o}$ & $\mathrm{o}$ & $\mathrm{o}$ & $\mathrm{o}$ \\
\hline b. Proper nouns and kinship terms & $\mathrm{O}$ & $\mathrm{O}$ & o & $\mathrm{O}$ & $\mathrm{O}$ \\
\hline c. (The definite article + ) participles (/adjectives) & o & o & & o & o \\
\hline d. Singular-plural asymmetry & some dialects & & & o & o \\
\hline e. An indefinite article + noun & & & & & o \\
\hline
\end{tabular}

Once the morphosyntactic variation in light of person agreement and the scopes of nominal expressions for imposters are clear, I analyze these properties in the following section.

\section{THE PERSON FEATURE AND DP}

After having observed two key properties of imposters cross-linguistically in the previous section, I adopt the general framework of the Minimalist Program proposed by Chomsky (2001). Lexical elements taken from the lexicon are fed to the syntax and sent to LF and PF via Spell-Out. My proposal consists of two components. First, I argue that under the DP hypothesis the D head is not always fully specified for the person feature. Second, I suggest that the variation in the scope of imposters results from a lexical gap of the D head. The proposed analysis accounts for agreement patterns observed cross-linguistically and the scope variation among the attested languages. It can extend to agreement patterns caused by non-imposters. I also compare the proposed analysis with three extant analyses of person agreement.

\section{A. The Person Feature on the D Head}

Since Abney's (1986), determiner elements such as definite and indefinite articles have been assumed to project Determiner Phrase (DP) (Bernstein, 2001; Longobardi, 2001; Adger, 2003; Alexiadou et al.; 2007; Cheng \& Sybesma; 1999, 2012; Lyutikova \& Pereltsvaig, 2015; Cyrino \& Teresa Espinal, 2015, to name only a few). This hypothesis adopts the perspective that the function of the $\mathrm{D}$ head is to mediate between the descriptions (predication) provided by the NP and a specific entity described in the world in all languages including article-less-languages such as Chinese and Japanese (e.g. Wang, 2009, Wu \& Bodomo 2009; Cheng \& Sybama, 1999, 2012, but Fukui, 1986 and his subsequent work). Concerning the person feature in DP, typologically it has been noticed that DP-internal concord never involves the realization of person (Baker, 2008). Carstens (2011, section 5) argues that the person feature is intrinsic to D. Danon (2011, p. 309) argues that a valued person feature is generated on the D head. Following Carstens and Danon, I assume that person is a feature of the D head in (22).

\footnotetext{
${ }^{3}$ Camacho (2018) reports that Spanish proper nouns can be accompanied by an indefinite determiner, as in (i).

(i) Nos han nombrado a un tal Blázquez.

CL have named DOM a so-called Blázquez
}

'They have imposed on us a 'so-called' Blázquez.'

While Blázquez is a proper noun, it possibly appears with an indefinite $u n$ and tal 'certain' in (i). According to Camacho, un tal + proper noun may be interpreted as definite in certain cases. Even though this expression is not used as an imposter, the definite reading of the DP appears to be consistent with (20e) in that an indefinite expression designate a unique individual in the given context. 


$$
\overbrace{\mathrm{D}[\text { Person] }}^{\mathrm{DP}} \mathrm{NP}
$$

In (22), the D head has the person feature and determines the referentiality of a DP associated with the discourse participants. Yet, there is no principle that D universally involves a specific value of the person feature in the lexicon particularly when it is not morphologically specified for person. I suggest that such a D head may obtain the person feature value extra-linguistically. When a full DP is used to refer to a speaker in the given context, D uniformly includes [Speaker] as INDEX feature cross-linguistically. However, the value of an INDEX feature for person does not always coincide with the same value of a CONCORD feature. This results in morphosyntactic variation in person agreement caused by imposters. When an imposter involves $\left[1^{\text {st }}\right]$ person, it determines a $1^{\text {st }}$ person reflexive in (23). The person feature of the imposter subject in (23) is shown in (24).

(23) This reporter sent myself to cover Bill Clinton's lecture at the Pavilion...

$$
=(1 \mathrm{a})
$$

(24) The person feature of the D head for this reporter

$$
\left[\begin{array}{lc}
\text { INDEX | PERSON } & \text { Speaker } \\
\text { CONCORD | PERSON } & 1^{\text {st }}
\end{array}\right]
$$

In (24) the CONCORD feature is $\left[1^{\text {st }}\right]$ and the imposter with it selects a $1^{\text {st }}$ person reflexive. This way $1^{\text {st }}$ person agreement comes about in imposter constructions. This is compatible with Wechsler \& Zlatić's (2003) matching constraints, which states that INDEX and CONCORD features match each other in that [Speaker] is identical to [1 $\left.{ }^{\text {st }}\right]$ in cross-linguistic pronominal systems.

However, regardless of whether a DP can be used to refer to a speaker or a third party, a full DP is not morphologically in a distinct form associated with a specific reference. This fact correlates with morphosyntactic variation person agreement caused by an imposter as observed in (11). Since non-pronominal DPs (that refer to a $3^{\text {rd }}$ party) are normally considered $3^{\text {rd }}$ person, one might state that an imposter taking a $3^{\text {rd }}$ person reflexive in (25) has [3 $\left.3^{\text {rd }}\right]$ as CONCORD feature, shown in (26).

(25) This reporter sees himself as managing editor in the future.

(26) The person feature of the D head for this reporter

$\left[\begin{array}{lc}\text { INDEX | PERSON } & \text { Speaker } \\ \text { CONCORD | PERSON } & 3^{\text {rd }}\end{array}\right]$

In (26) the CONCORD feature is $\left[3^{\text {rd }}\right]$ and the DP with $\left[3^{\text {rd }}\right]$ tolerates a $3^{\text {rd }}$ person reflexive. The agreement alternations in (23) and (25) may be taken as equivalent to Corbett's (2006) "semantic agreement" and "syntactic agreement" respectively in that the INDEX agreement is based on the semantics of the subject DP with a reference to a speaker while the CONCORD agreement is based on the morphology of the imposter DP as $3^{\text {rd }}$ person. However, this line of consideration cannot account for why underspecified person agreement is also possible in imposter constructions as observed in (9), repeated as (27).

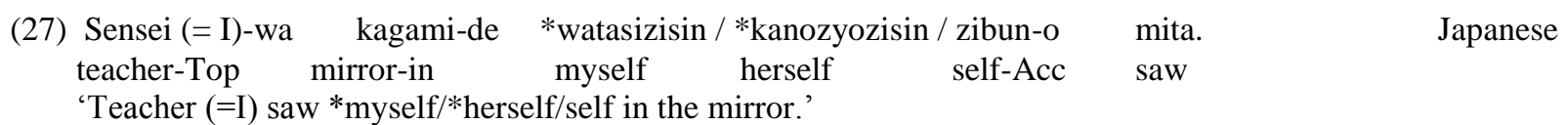

In (27) the imposter only selects the underspecified reflexive and does not determine a $1^{\text {st }}$ or $3^{\text {rd }}$ person reflexive although Japanese involves these lexical reflexives.

Alternatively, I propose that the D head of an imposter may not possibly have the value of a CONCORD feature for person in (28) because the head lacks a specific form relating to a reference.

(28) The person feature of the D head for an imposter referring to a speaker

$\left[\begin{array}{lc}\text { INDEX | PERSON } & \text { Speaker } \\ \text { CONCORD | PERSON } & \varnothing\end{array}\right]$

[ø] represents the lack of a specific value

In (28) the CONCORD feature for person is underspecified. Thus, Japanese allows the underspecified reflexive in binding while a $1^{\text {st }}$ person or $3^{\text {rd }}$ person reflexive cannot be selected in (27). On the other hand, in some languages such as English and Spanish the underspecification of the CONCORD feature is illicit and hence $3^{\text {rd }}$ person is selected as default/neutral form in PF (Ouhalla, 1993, Henderson, 2013, Baker, 2011, Furuya, 2017). The current analysis suggests that the variation in person agreement caused by imposter in (11) is attributed to distinct realizations of the CONCORD feature in PF (Bobaljik 2008), while person agreement in the constructions is uniform in narrow syntax for all languages.

Nonetheless, the proposed analysis of the two types of the person feature values for imposters cannot fully explain the cross-linguistic variation in the scope of the class of imposters in (21) since, unlike personal pronouns not all full DPs are possibly used to refer to discourse participants in one language and cross-linguistically. I suggest that the scope variation results from a lexical gap of the $\mathrm{D}$ head. When $\mathrm{D}$ does not involve a specific morphology associated to a specific discourse role, it is not always possible for the person feature on D to be specified for [Speaker] in one 
language or cross-linguistically. For example, to some speakers of English as well as speakers of Spanish and Icelandic, the D head needs to be specified for [Plural] for imposter use of a DP with the D head. The fact that the acceptability of the Icelandic word pessir fréttamenn 'these reporters' as imposter varies among speakers also comes from the possibility of specifying the D head for [Speaker]. Likewise, unlike other languages Spanish allows an indefinite determiner to have the person feature [Speaker] as in un servidor 'a servant' in given contexts. Since the D head that is morphologically underspecified for person, these language-specific and dialectal "adjustments" are applied for imposter use. If the proposed analysis is on the right track, the variations in imposter constructions come about in the lexicon and $\mathrm{PF}$, as illustrated in (25).

(25) The loci of the variation of the person feature

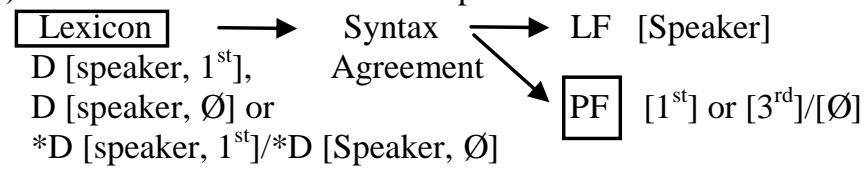

In the lexicon, there are three types of the person feature on D: (i) D with both the INDEX feature and the CONCORD feature specified for [Speaker] and [ $1^{\text {st }}$ ] respectively, (ii) D with [Speaker], and (iii) D that cannot have [Speaker]. Depending on which D is selected, the morphological realization of person and the (im)possibility of imposter use differ in one language and cross-linguistically. If an imposter DP as antecedent involves [ $1^{\text {st }}$, the bound object is a $1^{\text {st }}$ person reflexive. When the antecedent DP lacks $\left[1^{\text {st }}\right]$, the reflexive is a $3^{\text {rd }}$ person reflexive in some languages while Japanese determiners the underspecified reflexive. Moreover, full DPs are not always used as imposters since not all D can have [Speaker].

\section{B. Comparison of Analyses}

I compare the proposed analysis with three extant analyses of person agreement and show that these analyses have problematic points to account for the imposter data observed in this paper. The first analysis is based on data in prodrop languages, whereas the second and the third approaches build themselves on Spanish data.

The first approach adopts the null pronominal pro with $\left[1^{\text {st }}\right]$ in an imposter in (26).

(26) Pro approach
a. [DP pro $[\mathrm{NP}]]$
b. [PersonP pro [DP NP ]]
(Choi, 2013; Torrego \& Lake, 2015; Höhn, 2016)
(Höhn, 2016)

Once the null pronoun is projected on the top of DP, the person feature of the null pronominal element becomes that of the phrase (i.e. DP or PersonP). Given a pro analysis, the DP should involve a $1^{\text {st }}$ person pronoun for imposter use due to its reference. However, a main problem for (26) is that a DP with an overt pronoun behaves differently from what the pro hypothesis predicts in (27).

(27) a. We dancers need to keep ourselves/*themselves in good shape.

b. Them politicians and the Foreign minister devote *ourselves/themselves to soothing the barbarians.

In (27), the English pronoun-noun construction prohibits reflexives of distinct person from being bound, contrary to what the pro analysis predicts. This theory also cannot explain the fact that $3^{\text {rd }}$ person possibly yields a $1^{\text {st }}$ person reading. Moreover, it is not clear how cross-linguistic variation in the scope of imposters in (21) comes about in the pro analysis, although the same variation is not observable with overt pronouns. This weakens the pro analysis for imposter constructions.

A second approach proposes a complex DP consisting of an additional DP in its Spec and a clitics as the head in the DP, shown in (28).

(28) Dislocation approach (Ordóñez \& Treviño, 1999; Dudley, 2014, a.o.)

a. [DP DP $\left[3^{\text {rd }}\right]\left[\right.$, Clitics $\left.\left.\left[1^{\text {st }}\right]\right]\right]$

b. subject DP $\left[3^{\mathrm{rd}}\right] \quad$ V-clitic $\left[1^{\mathrm{st}}\right]$ reflexive $\left[1^{\mathrm{st}} / 3^{\mathrm{rd}}\right]$

In the middle of a derivation, the largest DP with the clitic as D head is projected in the subject position in (28a), and the clitics is attached to the verb in (28b). In this analysis, the languages that allow $1^{\text {st }}$ and $3^{\text {rd }}$ person agreement in imposter constructions select either the subject or the verbal morphology for agreement. If the subject is used as antecedent, $3^{\text {rd }}$ person agreement is observed. In contrast, the verbal morphology as antecedent determines $1^{\text {st }}$ person agreement. However, this theory also has the same problem as in (26) in light of $3^{\text {rd }}$ person agreement. The $3^{\text {rd }}$ person verbal morphology (as well as reflexives) is possible in imposter constructions. When a verb has a $3^{\text {rd }}$ person verbal morphology, this theory may not account for the $1^{\text {st }}$ person reading of imposters without additional stipulation. Furthermore, it is not clear whether it is possible to extend the analysis to the Japanese imposter construction (which displays underspecified agreement) and other languages that have the "poor" verbal morphology.

The last approach suggests a feature sharing operation held in LF for a $1^{\text {st }}$ person reading in (29). 
(29) LF-sharing approach (Ackema \& Neeleman 2013, p. 302)

[DP [ $\mathrm{pl}] \underbrace{\left[\mathrm{v} \text { verb }\left[1^{\mathrm{st}}, \mathrm{pl}\right]\right.}_{\text {(feature spreading in LF) }}$

In this analysis, an imposter is assumed to lack the person feature and obtains the value in LF via agreement between the subject and the verb. Again, this approach faces the same problem for $3^{\text {rd }}$ person of having a $1^{\text {st }}$ person interpretation. Moreover, it is not always the case that all languages possess the overt $1^{\text {st }}$ person verbal morphology even when it is possible to have a $1^{\text {st }}$ person reading. This also weakens a LF-sharing approach.

\section{CONCLUSION AND IMPLICATIONS}

I offered a comparative study of imposter constructions in Albanian, Bengali, Chinese, English, French, Icelandic, Italian, Japanese, Portuguese, Romanian, Spanish, and Turkish. I presented that an imposter referring to the speaker exhibits morphosyntactic variation in person agreement in these pro-drop and non-pro-drop languages. The variation falls into limited ways of morphological realization on the verbal morphology and reflexives: (i) $1^{\text {st }}$ person and $3^{\text {rd }}$ person, (ii) $1^{\text {st }}$ person, (iii) $3^{\text {rd }}$ person, and (iv) underspecified person in (11). I also showed that cross-linguistic variation in the scope of the class of imposters in Bengali, Chinese, English, Icelandic, and Spanish. Although languages tend to use definite DPs denoting humans as imposters, not all languages allow these expressions to be freely used to refer to a speaker or a speaker's group in one language and cross-linguistically in (21). I argued that the INDEX feature [Speaker] is not obligatorily linked to the CONCORD feature $\left[1^{\mathrm{st}}\right]$ on the $\mathrm{D}$ head of an imposter, which induces the morphosyntactic variation in PF. As for the scope variation, I claimed that the D head may or may not have the person feature cross-linguistically. This lexical gap of D in the lexicon leads to the scope variation. The proposed analysis is expected to extend to non-imposter constructions with the $\mathrm{D}$ heads that are not morphologically underspecified for person since these Ds may have lexical gaps as in imposter constructions, which are morphologically realized differently in PF. This prediction is borne out in (30).

(30) a. [The new me] takes better care of myself.

(http://anewscafe.com/2016/11/03/the-weight-is-over-week-46-miles-and-miles-of-milestons/)

b. [The real me] takes good care of herself.

(Adapted from http://www.dailykos.com/story/2015/10/24/1438740/-My-Old-Version-of-The-New-Me)

The subjects contain $1^{\text {st }}$ person pronouns inside called the person conversion construction (Bernstein 2008). This construction displays the agreement alternation. In the proposed analysis, the definite determiner in (30) is not morphologically underspecified for person and thus it can have [Speaker]. This INDEX feature on the D head may or may not be associated with the specific value of the CONCORD feature. If it is linked to $\left[1^{\text {st }}\right]$, a $1^{\text {st }}$ person reflexive is selected; otherwise a $3^{\text {rd }}$ person reflexive is selected in English. The present analysis also predicts that not all languages and/or dialects allow the conversion construction as well as the agreement alternation as in the case of imposter constructions, due to lexical gaps of the D heads for person. Furthermore, other constructions are also expected to show the same or similar agreement phenomena as imposter constructions. The answers to these predictions await for future research.

\section{REFERENCES}

[1] Abney, Steven. (1987). The English Noun Phrase in its Sentential Aspect. MIT dissertation.

[2] Ackema, Peter \& Ad Neeleman. (2013). Subset controllers in agreement relations. Morphology 23. 2, 291-323.

[3] Adger, David. (2003). Core Syntax: A Minimalist Approach. Oxford: Oxford University Press.

[4] Alexiadou, Artemis, Liliane Haegeman, \& Melita Stavrou. (2007). Noun phrase in the generative perspective. New York: Mouton de Gruyter.

[5] An, Feneun; Zhao, lei, \& Dong Cheng. (2016). A study on the referents of Chinese imposters. 91-100. Dong, Minghui; Lin, Jingia; Tang (eds.) Chinese lexical semantics 17th workshop, GLSW 2016 Singapore, Singapore, May 20-22, 2016.

[6] Akkuş, Faruk. (2017). Agreement and Anaphora in the Context of Imposters. Proceedings of the West Coast Conference on Formal Linguistics, ed. Aaron Kaplan et al., 24-31. Somerville, MA: Cascadilla Proceedings Project.

[7] Baker, Mark. (2008). The syntax of agreement and concord. Cambridge: Cambridge University Press.

[8] Baker, Mark. (2011). When agreement is for number and gender but not person. Natural Language \& Linguistic Theory 29. 4, 875-915.

[9] Bernstein, Judy B. (2008). The expression of third person in older and contemporary varieties of English. English Studies 89. 5, 571-86.

[10] Bernstein, Judy. (2001). The DP Hypothesis: Identifying Clausal Properties in the Nominal Domain. In Mark Baltin and Chris Collins (eds.), The Handbook of Contemporary Syntactic Theory. Oxford: Blackwell, 536-561.

[11] Bobaljik, Jonathan D. (2008). Paradigms, optimal and otherwise: A case for skepticism. In Asaf Bachrach and Andrew Nevins (eds.), Inflectional identity, 29-54. Oxford: Oxford University Press.

[12] Camacho, José. (2018). Un tal Ernestico/A certain Ernestico: on the structure of proper names, presented at the Hispanic Linguistic Symposium, at University of Texas, Austin, October 25-27, 2018.

[13] Carstens, Vicki. (2011). Hyperactivity and hyperagreement in Bantu. Lingua 121. 5, 721-741. 
[14] Cheng, Lisa L.-S. \& Rint Sybesm. (1999). 'Bare and Non-so-bare nouns and the structure of NP' Linguistic Inquiry 30. 4, 509542.

[15] Cheng, Lisa L.-S. \& Rint Sybesma. (2012). Classifiers and DP. Linguistic Inquiry 43.4, 634-650.

[16] Choi, Jaehoon. (2013). Pro-drop in pronoun-noun constructions. In Proceedings of the North East Linguistic Society, eds. Stefan Keine and Shayne Sloggett, 119-128. Amherst (MA): GLSA.

[17] Chomsky, Norm. (2001). Derivation by phase. In Ken Hale. A life in language, ed. Michael Kenstowicz, 1-52. Cambridge (MA), London: MIT Press.

[18] Chomsky, Noam. (1995). The Minimalist Program, MIT Press, Cambridge, MA

[19] Collins, Collins. (2014). Cross-linguistic studies of imposters and pronominal agreement. US: Oxford University Press.

[20] Collins, Chris \& Paul Postal. (2012). Imposters: A Study of Pronominal Agreement. MIT Press, Cambridge, MA.

[21] Corbett, Greville G. (2006). Agreement. Cambridge: Cambridge University Press.

[22] Cyrino, Sonia \& M Teresa Espinal. (2015). Bare nominals in Brazilian Portuguese: more on the DP/NP analysis. Natural Language \& Linguistic Theory 33. 2, 471-521.

[23] Danon, Gabi. (2011). Agreement and DP-internal feature distribution. Syntax 14.4, 297-317.

[24] Das, Satarupa. (2011). Bengali imposters. NYU Working Papers in Linguistics 3, 28-46.

[25] Dudley, Rachel. (2014). Spanish imposters and verbal agreement. In Chris Collins, (ed.), Cross-linguistic studies of imposters and pronominal agreement, 42-70. Oxford University Press, Oxford.

[26] Fukui, Naoki. (1986). A theory of category projection and its applications. Doctoral dissertation, MIT.

[27] Furuya, Kaori. (2016). PRO and (under)specification of person in imposter constructions. Theory and Practice in Language Studies 6, 1723-1731.

[28] Furuya, Kaori. (2017). Two types of the 3rd person feature in English?! Ampersand 4. 40-46.

[29] Harley, Heidi \& Ritter, Elizabeth. (2002). Person and Number: a feature-geometric analysis. Language 7.3, 482-526.

[30] Henderson, Brent. (2013). Agreement and person in anti-agreement. Natural Language \& Linguistic Theory 31. $2,453-481$.

[31] Höhn, Georg. F. K. (2016). Unagreement is an illusion: apparent person mismatches and nominal structure. Natural Language \& Linguistic Theory 543-592.

[32] Kallulli, Dalina. (2014). Some observations on imposters in Albanian. In Christ Collins (ed.), Cross-linguistic studies of imposters and pronominal agreement, 71-88. New York: Oxford University Press

[33] Kuno, Susumu. (1973). The Structure of the Japanese Language. MIT Press, Cambridge, MA.

[34] Kuroda, Sige-Yuki. (1973). Where epistemology, style and grammar meet: A case study from the Japanese. In Stephen Anderson \& Paul Kiparski (eds.), A Festschrift for Morris Halle, 377-391. Holt, New York.

[35] Longobardi, Giuseppe. (2001).The structure of DPs: Some principles, parameters, and problems. In Mark Baltin \& Chris Collins (eds.), The handbook of contemporary syntactic theory 562-603, Blackwell.

[36] Lyutikova, Ekaterina, \& Asya Pereltsvaig. (2015). The Tatar DP. Canadian Journal of Linguistics 60, $289-325$.

[37] Ordoñez, Francisco \& Esthela Treviño. (1999). Left dislocated subjects and the pro-drop parameter: A case study of Spanish. Lingua 107. 1, 39-68.

[38] Ouhalla, Jamal. (1993). Subject extraction, negation and the anti-agreement effect. Natural Language \& Linguistic Theory 11. $3,477-518$

[39] Servidio, Emilio. (2014). Imposters and secondary sources. In Christ Collins (ed.) Cross-linguistic studies of imposters and pronominal agreement, 121-143. New York: Oxford University Press.

[40] Siewierska, Anna. (2004). Person. Cambridge, England. Cambridge University Press.

[41] Soare, Gabriala. (2013). The syntax of some imposer DPs. Presented at 19th International Congress of Linguistics. Oral presentation. International Congress of Linguists, Geneva 20-27 July 2013. University of Geneva, Switzerland.

[42] Stirling, Lesley \& Rodney Huddleston. (2002). Deixis and Anaphora. In Rodney Huddleston and Geoffrey K. Pullum (eds.) The Cambridge Grammar of the English Language, 1449-1564. Cambridge, England. Cambridge University Press.

[43] Taylor, Michael. (2009). On the pronominal status of Brazilian Portuguese a gente. In NYU Working Papers in Linguistics, Vol 2: Papers in Syntax. 1-36.

[44] Torrego, Esther \& Itziar Laka. (2015). The syntax of $\varphi$-features: Agreement with plural DPs in Basque and Spanish. In Beatrice Fernández \& Pello Salaburu (eds.), Ibon Sarasola, Gorazarre. Homenatge, homenaje, 633-646. Bilbao: UPV/EHU.

[45] Vazquez Rojas, Violeta. (2014). Indefinite imposters. In Christ Collins (ed.) Cross-linguistic studies of imposters and pronominal agreement, 238-258. New York: Oxford University Press.

[46] Wang, Chyan-an Arthur. (2009). NYU Working Papers in Linguistics, Volume 2: Papers in Syntax.

[47] Wechsler, Stephen. (2011). Mixed agreement, the person feature and the index/concord distinction. Natural Language \& Linguistic Theory 29.4, 999-1031.

[48] Wechsler, Stephen, \& Larisa Zlatić. (2003). The many faces of agreement. Stanford: CSLI.

[49] Wood, Jim \& Einar Freyr Sigurdsson. (2014). Icelandic verbal agreement and pronoun-antecedent relations. In Chris Collins (ed.), Cross-linguistic studies of imposters and pronominal agreement, 196-237. New York: Oxford University Press.

[50] Wu, Yicheng \& Adams Bodomo. (2009). Classifiers $\neq$ determiners. Linguistic Inquiry 40. 3, 487-503.

Kaori Furuya received her Ph.D. degree from the Graduate Center, City University of New York in 2009. The title of the dissertation is The DP Hypothesis through the Lens of Japanese Nominal Collocation. She is an assistant professor at University of North Texas, USA. She is interested in theoretical linguistics. Her recent publications are as follows:

1. (2017). Two types of $3^{\text {rd }}$ person in English?! Ampersand 4, 40-46.

2. (2017). (Under)specification of the person feature in relative clauses, Acta Linguistica Hungarica 64. 2, 281-311

3. (2018) A reconsideration of the (non-)uniform syntax of Korean right- dislocation. Linguistic Research 35. 2, 275-304. 